\title{
Epidermoid Cyst in the Cerebellopontine Angle: Technical Description Video
}

\author{
Marcus Vinicius de Morais ${ }^{1}$ Romulo Almino de Alencar Arrais Mota ${ }^{1}$ Thais Aparecida Marques ${ }^{1}$ \\ Rafael Duarte de Souza Loduca ${ }^{1}$ Paulo Mácio de Porto Melo ${ }^{1}$ \\ ${ }^{1}$ Department of Neurosurgery, Hospital Militar de Área de São Paulo, \\ São Paulo, Brazil \\ J Neurol Surg B 2019;80(suppl S3):S325-S326. \\ Address for correspondence Marcus Vinicius de Morais, MD, \\ Department of Neurosurgery, Hospital Militar de Área de São Paulo, \\ Rua Vergueiro, 4241 Apto 91, CEP 04101-300, São Paulo, SP, Brazil \\ (e-mail: moraisneuro@gmail.com).
}

\begin{abstract}
Keywords

- epidermoid cyst

- cerebellopontine angle lesion

- cerebellopontine angle microsurgery

- epidermoid cyst surgery

Objectives To describe the operative technique for treatment of epidermoid cysts in the cerebellopontine angle (CPA).

Design The present video is a case report.

Setting Patient is positioned in three-quarters prone. Retrosigmoid approach should be made under neurological monitoring and with neuronavegation to help achieve maximal safe resection. The skin incision is vertical, slightly curved, $5 \mathrm{~mm}$ medial to the mastoid notch. Craniectomy is superiorly limited by the transverse sinus and laterally limited by the sigmoid sinus. A C-shaped durotomy is made with its base protecting the sigmoid sinus. The lesion is removed in piecemeal fashion (-Fig. 1). The neurological monitoring helps.

Results The patient was discharged 2 days later without neurological deficits.

Conclusions The surgical treatment associated with neurological monitoring and neuronavegation is a safe procedure to treat epidermoid cysts in the CPA.

The link to the video can be found at: https://youtu.be/sEuFyq9c2sw.
\end{abstract}

Conflict of Interest

None to disclose.

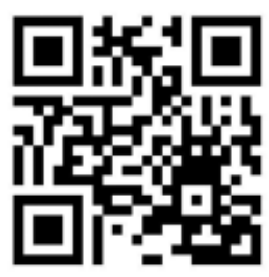

received

June 1, 2018

accepted after revision

November 11, 2018

published online

January 8, 2019

www.thieme.com/skullbasevideos

www.thieme.com/jnlsbvideos

DOI https://doi.org/

10.1055/s-0038-1676997.

ISSN 2193-6331.
๑) 2019 Georg Thieme Verlag KG
Stuttgart · New York

License terms

(c) (1) $\ominus$ (\$) 
S326 Epidermoid Cyst in CPA de Morais et al.

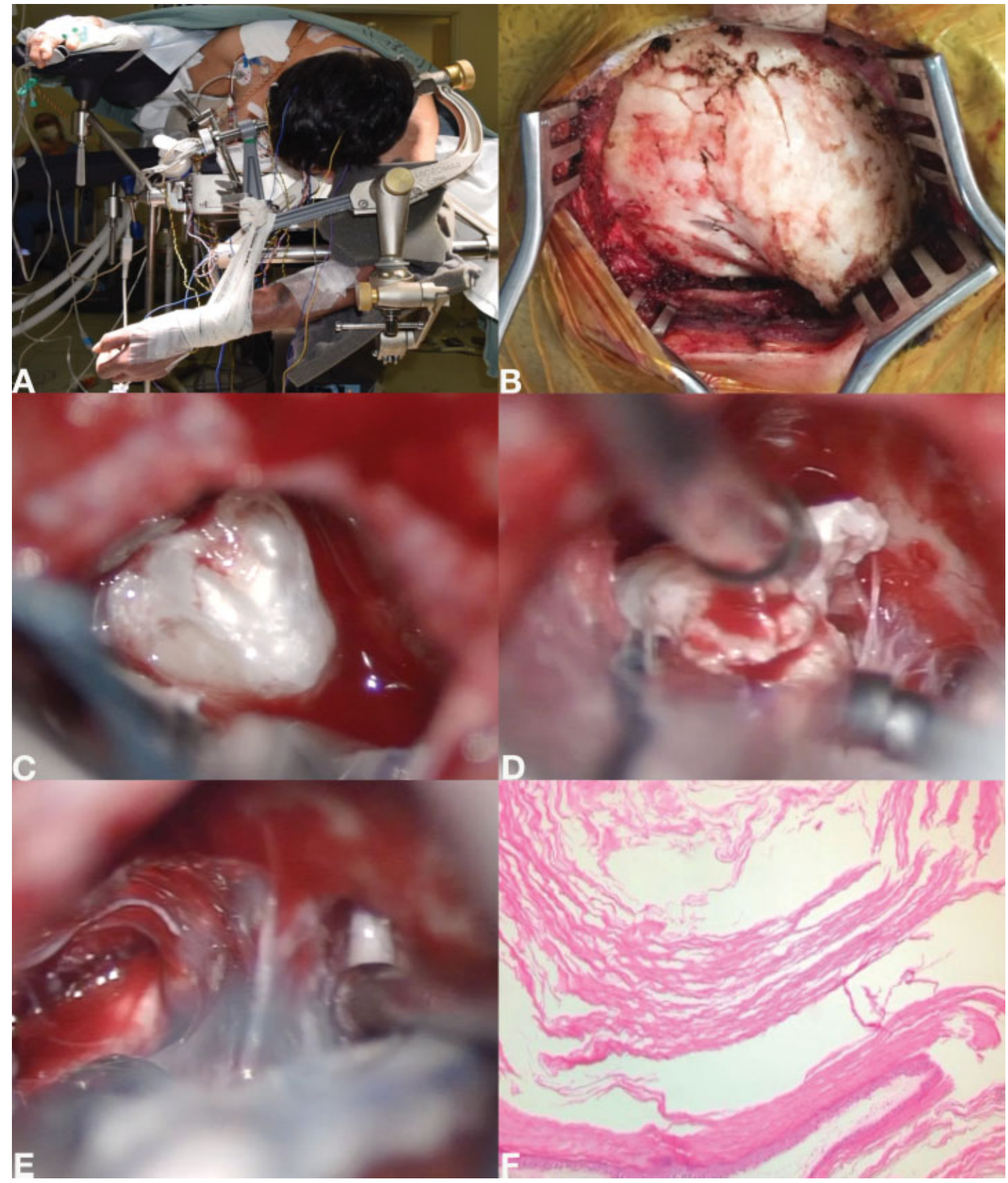

Fig. 1 Intraoperative images. (A) Patient position, (B) asterion exposure, (C) epidermoid cyst identification, (D) lesion removal in piecemeal fashion, (E) intraoperative neurological monitoring, (F) anatomopathological study confirming the diagnosis. 